\title{
Effect of Nebulized 3\% Hypertonic Saline on Intensive Care Unit Admission Rates of Infants with Moderate Acute Bronchiolitis
}

Jose Carlos Flores-González ${ }^{1 *}$, Patricia Rodríguez-Campoy ${ }^{1}$, Juan Pérez-Guerrero ${ }^{1}$, Belén Serrano-Moyano ${ }^{1}$, Encarnación Palma-Zambrana ${ }^{1}$, Paloma Comino-Vázquez ${ }^{1}$, Gema Jiménez González ${ }^{2}$ and Alfonso M Lechuga-Sancho ${ }^{1,3}$

${ }^{1}$ Clinical Pediatrics Department, Hospital Universitario Puerta del Mar, Cádiz, Spain

${ }^{2}$ Foundation for the Management of Biomedical Research, Cádiz, Spain

${ }^{3}$ Maternal and Child Health Care and Radiology Department, University of Cádiz, Cádiz, Spain

*Corresponding author: Jose Carlos Flores González, Pediatrics Department, University Hospital Puerta del Mar, Cádiz, Spain, Tel: + 34-956-002-255; Fax: + 34956004803; E-mail: carlosflogon@gmail.com

Received date: August 02, 2016; Accepted date: August 15, 2016; Published date: August 16, 2016

Copyright: (C) 2016 Flores-Gonzalez JC, et al. This is an open-access article distributed under the terms of the Creative Commons Attribution License, which permits unrestricted use, distribution, and reproduction in any medium, provided the original author and source are credited

\section{Abstract}

Objectives: To investigate whether the use of nebulized $3 \%$ hypertonic saline in infants hospitalized for acute bronchiolitis reduces their rate of pediatric intensive care unit (PICU) admission, the mean length of PICU stay and total hospital stay.

Methods: Cross-sectional study including 626 infants hospitalized for moderate acute bronchiolitis comparing a group receiving nebulized 3\% hypertonic saline (HS group) between September 2011 and May 2014 (n=320), with a historic control group treated with normal saline (NS group) between September 2007 and May 2010 ( $n=306$ ) independently of the concomitant use of bronchodilators.

Results: Overall hospital stay including days at PICU, was significantly reduced in HS group (4 days (0-46) vs 5 days (1-73); $p<0.0001)$. However, we did not find a significant reduction in PICU admission rate in the HS group $(p=0.115)$, neither in the length of stay (LOS) in PICU (5 days (1-30) vs 6 days $(1-26) ; p=0.402)$. Half as many admission were observed in patients with risk factors of severe disease in HS group $(6.5 \%$ of those with risk factors vs $3.1 \%$ of those without risk factors), although this failure to find a difference $(p=0.136)$.

Conclusions: Treatment with nebulized $3 \%$ hypertonic saline was not accompanied by a reduction in PICU admission. There was no difference in PICU length of stay in infants with acute bronchiolitis, and admission rates in infants with risk factors for serious bronchiolitis; it was also associated with a significantly shorter mean hospital stay.

Keywords: $3 \%$ hypertonic saline; Admission; Bronchiolitis; Pediatric intensive care unit

\section{Abbreviations}

RSV: Respiratory Syncytial Virus; WDF: Wood-Downes Clinical Scoring System Modified by Ferres

\section{Introduction}

Acute bronchiolitis is the most common lower respiratory tract infection in infants [1]. It is most frequently caused by the respiratory syncytial virus (RSV), and most cases are self-limited and may be treated symptomatically on an outpatient basis. A small proportion of patients however, require hospital admission, although this rate varies widely between series, mainly due to substantial variations in admission criteria [1]. Following a considerable increase between 1980 and 1996 [2], admission rates began to stabilize and are now approximately $2-5 \%[3,4]$. Similar rates have been reported in our setting [5].

The proportion of hospitalized infants with acute bronchiolitis requiring pediatric intensive care also varies between groups, with rates ranging from $3 \%$ to $15 \%$ [6-10]. However, when analyzing the infant population with increased risk for serious disease, their PICU admission rates increase as much as to $50 \%[11,12]$. One likely explanation for such variations is the lack of scientific evidence on the criteria for PICU admission. Standard criteria include severe or rapidly progressing respiratory failure, blood oxygen saturation $<90 \%$ with a fraction of inspired oxygen $\left(\mathrm{FiO}_{2}\right)$ of over $40 \%$, consciousness impairment, apneas, and severe acidosis [1]. Although an age below 3 months, and particularly 6 weeks, is not an absolute criterion for PICU admission, it has been found to be a factor for developing serious disease and therefore the need of hospitalization [13].

Treatment with nebulized 3\% hypertonic saline may rehydrate the airway surface liquid and increase mucociliary clearance, so it has emerged as a novel treatment for acute bronchiolitis in recent years. Most studies and systematic reviews have demonstrated that it shortens length of hospital stay and contributes to faster clinical improvement based on disease severity scales [14-16]. Reduced hospitalization rates were also reported in a recent meta-analysis [17]. The last clinical practice guideline, recommends clinicians to administer nebulized hypertonic saline to inpatient infants as a safe and effective measure at improving symptoms and reducing hospital LOS in moderate acute bronchiolitis [18]. However, to the best of our knowledge, there are yet no studies analyzing PICU admission rates with the use of nebulized $3 \%$ hypertonic saline. 
Citation: Flores-Gonzalez JC, Rodríguez-Campoy P, Pérez-Guerrero J, Serrano-Moyano B, Palma-Zambrana E, et al. (2016) Effect of Nebulized 3\% Hypertonic Saline on Intensive Care Unit Admission Rates of Infants with Moderate Acute Bronchiolitis. J Clin Res Bioeth 7: 281. doi: $10.4172 / 2155-9627.1000281$

Page 2 of 5

The aim of this work was to investigate whether the use of nebulized $3 \%$ hypertonic saline, with or without bronchodilators, in hospitalized infants with moderate acute bronchiolitis reduces PICU admission rates as compared to the use of normal saline. Secondarily, we aimed to compare PICU admission rates in the subgroup of infants with risk factors of developing severe disease, the need for mechanical ventilation, and mean lengths of PICU and total hospital stays.

\section{Patients and Methods}

We performed a comparative study with a historical control group, using data collected retrospectively during 3 epidemic years (September 2007 to May 2010, NS group), and prospectively during the following 3 epidemic years (September 2011 to May 2014, HS group).

\section{Patients}

We included all infants under 2 years of age, admitted to our pediatric ward at Hospital Universitario Puerta del Mar in Cádiz (Spain), with a diagnosis of moderate acute bronchiolitis according to the International Diseases Classification, Ninth revision, code 466.1, during both study periods (2007-2010 and 2011-2014). The diagnosis of bronchiolitis was based on a first episode of respiratory distress with wheezing, preceded by an infection of the upper respiratory airways. We excluded patients with previous episodes of wheezing or a diagnosis of asthma. To analyze the effect of 3\% hypertonic saline nebulization on admission to the PICU, we registered as admitted to PICU only those who had received more than three nebulizations prior to PICU admission. The criteria for admission to PICU were the same in both periods: severe respiratory failure (score $>7$ according to the Wood-Downes Clinical Scoring System modified by Ferres [WDF] (Table 1) [19], blood oxygen saturation below 90\% whilst receiving a $\mathrm{FiO}_{2}$ of over $40 \%$, consciousness impairment, apneas, respiratory acidosis $(\mathrm{pH}<7.1)$, or rapidly progressing disease at any time during hospitalization.

\begin{tabular}{|c|c|c|c|c|}
\hline & 0 & 1 & 2 & 3 \\
\hline Wheezing & None & $\begin{array}{l}\text { End } \\
\text { expiration }\end{array}$ & $\begin{array}{l}\text { Entire expiratory } \\
\text { phase }\end{array}$ & $\begin{array}{l}\text { Inspiration and } \\
\text { expiration }\end{array}$ \\
\hline Retractions & None & $\begin{array}{l}\text { Subcostal } \\
\text { or lower } \\
\text { intercostal }\end{array}$ & $\begin{array}{l}\text { 1+superclavicular } \\
\text { +nasal flaring }\end{array}$ & $\begin{array}{l}\text { 2+suprasternal } \\
\text { +lower } \\
\text { intercostal }\end{array}$ \\
\hline $\begin{array}{l}\text { Respiratory } \\
\text { rate, } \\
\text { breaths/min }\end{array}$ & $<30$ & $31-45$ & $46-60$ & $>60$ \\
\hline $\begin{array}{l}\text { Heart rate, } \\
\text { beats } / \mathrm{min}\end{array}$ & $<120$ & $>120$ & & \\
\hline $\begin{array}{l}\text { Inspiratory } \\
\text { breath } \\
\text { sounds }\end{array}$ & Normal & $\begin{array}{l}\text { Regular, } \\
\text { equal }\end{array}$ & $\begin{array}{l}\text { Markedly silent, } \\
\text { equal }\end{array}$ & $\begin{array}{l}\text { Silent thorax, no } \\
\text { wheezing }\end{array}$ \\
\hline Cyanosis & No & Yes & & \\
\hline
\end{tabular}

${ }^{*}$ A score of 1-3 points denotes mild bronchiolitis; 4-7 moderate bronchiolitis; and 8-14 severe bronchiolitis.

Table 1: Wood-Downes clinical scoring system scale modified by Ferres*.
We excluded those admitted to the PICU directly from the pediatric emergency department, or referred from different hospitals, and those from our own department who had been on the ward for less than 24 hours or had received fewer than three nebulization.

\section{Study design}

For the first period of the study (retrospective phase), we performed a chart review of all infants who met the study inclusion criteria and were discharged with a diagnosis of acute bronchiolitis between September 2007 and May 2010 (NS group). These patients had been treated mainly with bronchodilators (salbutamol or epinephrine) nebulized in saline, in addition to standard support measures. The interval between nebulization varied according to the criteria of the attending pediatrician. The following additional data were recorded for each patient: age, sex, risk factor(s) for serious disease, length of hospital stay, WDF score at hospital admission, RSV infection (based on the detection of antigen in nasopharyngeal aspirate), treatment received for this episode prior to admission (salbutamol, corticosteroids, or antibiotics), and treatment during admission (nebulized saline with salbutamol or epinephrine). We also recorded the reason for admission to the PICU, the use of mechanical ventilation, and the duration of both of these.

Starting on September 2011, our institution adopted a new treatment protocol for infants with acute moderate bronchiolitis, changing the use of normal saline to $3 \%$ hypertonic saline with or without added bronchodilators, according to the incipient evidence favouring the newer therapy [1]. For the prospective part of the study, we collected the same variables for all infants with a diagnosis of acute bronchiolitis who met the inclusion criteria between September 2011 and May 2014 (HS group). These patients were treated with nebulized $3 \%$ hypertonic saline with or without bronchodilators (salbutamol or epinephrine), in addition to the same standard support measures. The interval between nebulizations was also left to the discretion of the attending pediatrician.

We excluded all patients of the 2010-2011 season, considering it a transition period in which it was possible for a patient to receive both types of nebulizations within the same admission.

The nebulized solution was administered in both groups using an ultrasonic hospital nebulizer (Shinmed model Sw918, Shining world health care CO, LTD, New Tapiei City, Taiwan). We registered as risk factors for serious disease to have been born preterm, to suffer a congenital cardiopathy, or bronchopulmonar dysplasia, immunodeficiency disorder, or any neuromuscular disorder.

\section{Statistical Analysis}

We used the $\chi^{2}$ test to analyze differences between qualitative variables. Where appropriate, the Fisher exact test was used for binary variables. We applied the Kolmogorov-Smirnov test to test for normal distribution of quantitative variables. Parametric and nonparametric quantitative variables were compared using Student's T-test and the Mann-Whitney U test, according to their distribution. Significance was considered at a $\mathrm{p}$ value of $<0.05$.

\section{Ethics}

The study was approved by the research ethics committee of Hospital Universitario Puerta del Mar, and signed informed consent 
Citation: Flores-Gonzalez JC, Rodríguez-Campoy P, Pérez-Guerrero J, Serrano-Moyano B, Palma-Zambrana E, et al. (2016) Effect of Nebulized 3\% Hypertonic Saline on Intensive Care Unit Admission Rates of Infants with Moderate Acute Bronchiolitis. J Clin Res Bioeth 7: 281. doi: $10.4172 / 2155-9627.1000281$

Page 3 of 5

was obtained from the parents or legal representatives of the infants who participated in the prospective stage of the study.

\section{Results}

A total of 626 patients with acute moderate bronchiolitis were included in the study; $306(48.9 \%)$ had been treated with nebulized saline (NS group) and 320 (51.1\%) with nebulized 3\% hypertonic saline (HS group). We found no differences between groups in disease severity as measured by the WDF score at admission (group 0:5 (2-9) vs group 1:5 (1-10), $\mathrm{p}=0.127$, proportion of positive RSV tests (195 (63.9\%) vs 207 (64.7\%), $\mathrm{p}=0.603)$, or in the number of patients with risk factors for serious disease $(49(16 \%)$ vs $39(12.2 \%), p=0.169)$. Preadmission use of salbutamol, was significantly higher in NS group $(\mathrm{p}<0.004)$ but there was no difference in the pre-admission use of corticosteroids or antibiotics ( $\mathrm{p}=0.366$ and $\mathrm{p}=0.347$, respectively) (Table 2). The number of patients admitted per epidemic year was similar in both groups (Figure 1), and there is not difference in the mean age between groups $(\mathrm{p}=0.113)$.

Bronchodilators employed in NS group (nebulized in $0.9 \%$ saline), were salbutamol in 99 cases (32.4\%) and epinephrine in 205 (67\%). HS group received salbutamol in 24 (7.5\%), epinephrine in 181 (56.7\%) and no bronchodilator in $35.9 \%$ of cases.

\begin{tabular}{|l|l|l|l|}
\hline Variable & NS Group & HS Group & p \\
\hline Patients (n) & 306 & 320 & \\
\hline Mean age (months) & $2.1(0.3-24.28)$ & $2.0(0.16-15.34)$ & 0.113 \\
\hline Male sex (n and \%) & $186(60.8 \%)$ & $175(54.7 \%)$ & 0.123 \\
\hline $\begin{array}{l}\text { Presence of risk factors } \\
\text { for serious disease (n and } \\
\%)\end{array}$ & $49(16 \%)$ & $39(12.2 \%)$ & 0.169 \\
\hline $\begin{array}{l}\text { WDF score on admission } \\
\text { (Score and range) }\end{array}$ & $5(2-9)$ & $5(1-10)$ & 0.127 \\
\hline $\begin{array}{l}\text { Positive RSV test (n and } \\
\%)\end{array}$ & $195(63.9 \%)$ & $207(64.7 \%)$ & 0.169 \\
\hline $\begin{array}{l}\text { Patients receiving } \\
\text { Salbutamol prior to } \\
\text { admission (n and \%) }\end{array}$ & $120(43 \%)$ & $101(31.6 \%)$ & 0.004 \\
\hline $\begin{array}{l}\text { Patients receiving } \\
\text { Corticosteroids prior to } \\
\text { admission (n and \%) }\end{array}$ & $56(20.1 \%)$ & $74(23.1 \%)$ & 0.366 \\
\hline $\begin{array}{l}\text { Patients to } \\
\text { Antibiotics prior } \\
\text { admission (n and \%) }\end{array}$ & $21(7.5 \%)$ & Ferres, \\
\hline $\begin{array}{l}\text { WDF=Wood-Downes clinical scoring system } \\
\text { RSV=Respiratory Syncytial Virus. }\end{array}$ & & \\
\hline
\end{tabular}

Table 2: Baseline demographic, clinical, and therapeutic characteristics of infants with acute bronchiolitis treated with normal saline (NS group) or $3 \%$ Hypertonic saline (HS group).

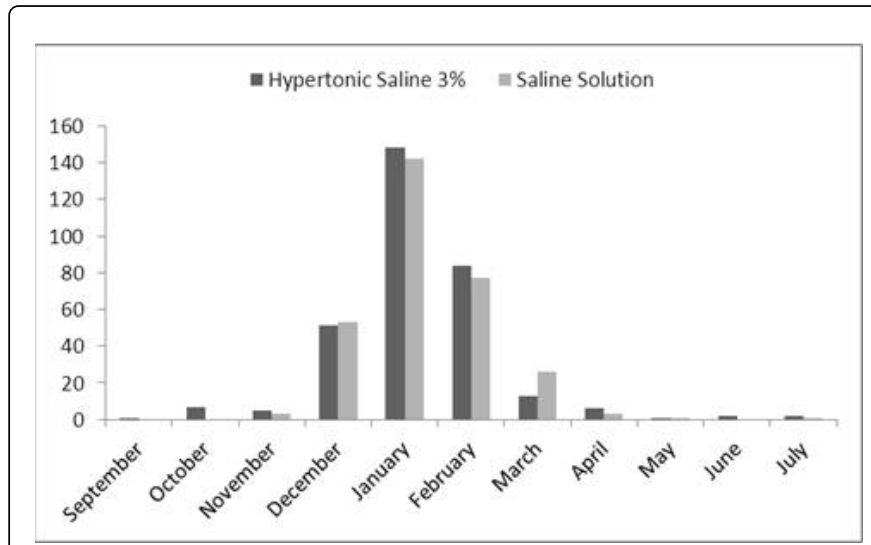

Figure 1: Seasonal pattern for September 2007 to May 2010 and September 2011 to May 2014: number of patients in each treatment group by month.

\section{Primary and secondary outcomes}

Admission rates to the PICU were 53 out of 306 (17.3\%) in NS group and 41 out of $320(12.8 \%)$ in HS group ( $p=0.115)$. Median of length of intensive care stay was one day shorter in the group receiving $3 \%$ HS, though this difference did not reach statistical significance $(6$ (1-26) vs 5 days (1-30), $\mathrm{p}=0.402)$. Mechanical ventilation was required in $18(34 \%)$ of the 53 children admitted to the PICU in NS group and in $9(22.5 \%)$ of the 41 children admitted in HS group $(\mathrm{p}=0.228)$. Mechanical ventilation was required for 6.5 (3-18) days in NS group compared with 7 (4-10) days in HS group, but again, this difference was not significant (0.717). PICU admission rates remained similar in both groups also, after age-stratified analysis (Table 3 ).

Of the 626 patients analyzed overall, 538 (85.9\%) had no risk factors for serious disease, $68(10.9 \%)$ had been born preterm, 11(1.8\%) had congenital cardiopathy, 1 (0.2\%) had an immunodeficiency disorder, and $6(1 \%)$ had a neuromuscular disorder. The distribution of these conditions was similar in both groups $(49(16 \%)$ vs $39(12.2 \%)$; $\mathrm{p}=0.169$. In total, $30(34 \%)$ of the 86 patients with risk factors were admitted to the PICU. The rate of high risk patients needing PICU was $20(40.8 \%)$ in NS group versus $10(25.6 \%)$ in HS group, this difference however, was not significant $(\mathrm{p}=0.136)$. As expected, the overall PICU admission rate for patients without risk factors was significantly lower than for patients with risk factors: $64(11.9 \%)$ vs $30(34 \%) ; \mathrm{p}<0.0005)$. Within these patients without risk factors, treatment option did not make a difference either in PICU admission rates; 33 (12.8\%) were from NS group and 31 (11\%) from HS group). Nine (30\%) of the patients with risk factors required mechanical ventilation.

\begin{tabular}{|l|l|l|l|}
\hline \multirow{2}{*}{ Age (months) } & \multicolumn{3}{|l|}{ Admission to Intensive Care Unit } \\
\cline { 2 - 4 } & Group 0 n (\%) & Group 1 n (\%) & p \\
\hline$<1$ & $12(3.9 \%)$ & $15(4.6 \%)$ & 0.796 \\
\hline $1-3$ & $24(7.8 \%)$ & $19(5.9 \%)$ & 0.272 \\
\hline $3-6$ & $12(3.9 \%)$ & $5(1.5 \%)$ & 0.098 \\
\hline$>6$ & $5(1.6 \%)$ & $2(0.6 \%)$ & 0.523 \\
\hline
\end{tabular}

Table 3: Admission rate to pediatric intensive care unit (ICU) by age. 
Length of hospital stay was significantly reduced in HS group (5 (1-73) vs $4(0-46)$ days; $\mathrm{p}<0.0001)$. During their stay, $56(20.1 \%)$ of the infants in NS group and $74(23.1 \%)$ of those in HS group received corticosteroids at some point $(\mathrm{p}=0.366)$. The corresponding rates for antibiotic treatment were $21(7.5 \%)$ and $18(5.6 \%)$ respectively $(\mathrm{p}=0.347)$.

\section{Discussion}

In our study, the admission rates to the PICU of infants with acute bronchiolitis were similar in infants treated with nebulized $3 \%$ hypertonic saline and normal saline $(\mathrm{p}=0.876)$. In accordance with other authors, shorter hospital stays [16] were observed in infants treated with $3 \%$ hypertonic saline. Hypertonic saline receiving infants admitted to the PICU stayed in this unit for one day less than infants admitted while receiving physiological saline, but this one day difference was not statistically significant, probably due to the small overall number of patients needing PICU. Nor did we find any significant differences between groups in the need for mechanical ventilation $(p=0.228)$, or duration of ventilation $(p=0.717)$, so these factors are unlikely the reason for the one day shorter PICU stay of the $3 \% \mathrm{HS}$ receiving group. We observed no differences between the groups for admission to the PICU, even after stratification by age.

Similarly, two recent series have failed to find differences in PICU admission rates in patients receiving $3 \%$ hypertonic saline versus those receiving physiological saline. However, this comparison was not the primary aim of any of these studies. Both of them, report an overall length of hospital stay similar to our series, but in contrast with our results, none of these two find a shorter length of stay in the group receiving $3 \%$ Hypertonic saline $[20,21]$.

Although several factors have been associated with an increased risk of severe disease, most infants with acute bronchiolitis admitted to the PICU are reported to be previously healthy and not considered of high risk $[22,23]$. The rate of patients with high risk factors admitted to the intensive care unit in our sample was $6.5 \%$ in the group receiving physiological saline and $3.1 \%$ in the group with $3 \%$ hypertonic saline, similar to that described in other series. Thus, in this sub-group of patients with risk factors, receiving $3 \%$ hypertonic saline reduces by half the requirement of PICU admission. This difference did not reach statistical significance (probably due to the small overall number of such patients admitted to the PICU), however, it may well be clinically relevant.

Length of hospital stay was significantly shorter in the $3 \%$ hypertonic saline group, which is consistent with previous reports [16,21-26]. The use of corticosteroids and antibiotics during hospitalization was similar in both groups, so these are unlikely to account for such difference.

Numerous studies have shown considerable variations in how acute bronchiolitis is managed [27-29]. The fact that many patients progress adequately regardless of the treatment received, probably explains why drugs without a proven clinical benefit are still used, with many professionals being guided more by personal or institutional preferences, rather than by an objective assessment of disease severity [27-29]. We observed a higher use of inhaled salbutamol prior to admission in the NS group and the same use of oral corticosteroids during admission although these treatments are not supported by current evidence.
The main limitation of our study is the use of a historical control group. Although we think that this limitation may not affect the results because the two periods analyzed were relatively close in time, and bronchiolitis treatment plans by primary care physicians don't appear to have changed so much. Nevertheless, we believe our findings are clinically relevant, since it was in the second group, in which the preadmission use of salbutamol was significantly lower, in whom we observed a shorter mean hospital stay. Our findings add weight to the growing evidence that nebulized 3\% hypertonic saline solution has beneficial effects in infants with acute bronchiolitis with a median stay above 3 days.

\section{Conclusions}

We observed no difference nor in PICU admission, either in PICU stay in patients with a moderate acute bronchiolitis treated with $3 \%$ hypertonic saline compared with those treated with normal saline. In the subgroup of patients with a history of risk factors for serious disease, there was a not statically significant reduction in admissions to intensive care in patients receiving nebulized 3\% hypertonic saline. Larger series are needed to determine whether or not nebulized $3 \%$ hypertonic saline significantly reduces PICU admission in patients with risk factors. In accordance with reports in the literature, patients treated with $3 \%$ hypertonic saline in our series, had significantly shorter hospital stays compared with those treated with normal saline.

\section{Acknowledgments}

This study would not have been possible without the help and professional support of the Membership of the Bronchiolitis of Cadiz Study group (BronCaS): Antonio Atienza-Contreras, Mirian AragónRamírez, $M^{a}$ Teresa Domínguez-Coronel, Paula Jiménez-Cerrato, Miguel Ángel Matamala-Morillo, Patricia Rodríguez-Campoy, Rosa García-Ortega, Juan Jesús Pérez-Guerrero, Laura García-García, Francisco Javier Dávila-Corrales, Belén Serrano-Moyano, Encarnación Palma-Zambrana, Paloma Comino-Vázquez, Ana Estalella-Mendoza, Sonia Garófano-Montero, Isabel Calvo-Morales and Branislava Grujic. We thank Mónica Saldaña for her support in the early stages of the study, as well as María Victoria García-Palacios and the staff in the hospital pharmacy department, especially Rocío Bulo.

\section{Conflicts of Interest and Source of Funding}

This study was partially funded by grants from the Spanish Ministry of Health, Social Politics and Equality for the promotion of independent clinical research (EC10-180).

\section{References}

1. (2010) Grupo de trabajo de la Guía de Practica Clínica sobre la Bronquiolitis Aguda In: Guía de Practica Clínica sobre la Bronquiolitis Aguda, Guía de Práctica Clínica en el SNS: Plan de Calidad para el Sistema Nacional de Salud (SNS) del Ministerio de Sanidad y Política Social, AATRM 2007/05

2. Shay DK, Holman RC, Newman RD, Liu LL, Stout JW (1999) Bronchiolitis-associated hospitalizations among US children, 1980-1996. JAMA 282: 1440-1446.

3. Stockman LJ, Curns AT, Anderson LJ, Fischer-Langley G (2012) Respiratory syncytial virus-associated hospitalizations among infants and young children in the United States, 1997-2006. Pediatr Infect Dis J 31: 5-9.

4. Iwane MK, Edwards KM, Szilagyi PG (2004) Population-based surveillance for hospitalizations associated with respiratory syncytial 
Citation: Flores-Gonzalez JC, Rodríguez-Campoy P, Pérez-Guerrero J, Serrano-Moyano B, Palma-Zambrana E, et al. (2016) Effect of Nebulized 3\% Hypertonic Saline on Intensive Care Unit Admission Rates of Infants with Moderate Acute Bronchiolitis. J Clin Res Bioeth 7: 281. doi: $10.4172 / 2155-9627.1000281$

Page 5 of 5

virus, influenza virus, and parainfluenza viruses among young children. Pediatrics 113: 1758-1764.

5. Bonillo Perales A, Delgado D, Rubio J, Ortega M (2000) Perinatal antecedents associated with hospitalization for bronchiolitis. A comparison with the Impact-RSV Study Group. An Esp Pediatr 53: 527-532.

6. Bonillo PA, DiezDelgado RJ, Ortega MA (2000) Perinatal history and hospitalization for bronchiolitis. A comparison with the impact-RSV Study Group. An Esp Pediatr 53: 527-532.

7. Soilly AL, Ferdynus C, Desplanches O, Grimaldi M, Gouyon JB (2012) Paediatric intensive care admissions for respiratory syncytial virus bronchiolitis in France: Results of a retrospective survey and evaluation of the validity of a medical information system programme. Epidemiol Infect 140: 608-616.

8. Prais D, Schonfeld T, Amir J (2003) Admission to the intensive care unit for respiratory syncytial virus bronchiolitis: a national survey before palivizumab use. Pediatrics 112: 548-552.

9. Vicente D, Montes M, Cilla G, Perez-Yarza EG, Perez-Trallero E (2003) Hospitalization for respiratory syncytial virus in the paediatric population in Spain. Epidemiol Infect 131: 867-872.

10. Purcell K, Fergie J (2004) Driscoll Children's Hospital respiratory syncytial virus database: risk factors, treatment and hospital course in 3308 infants and young children, 1991 to 2002. Pediatr Infect Dis J 23: 418-423.

11. Clark SJ, Beresford MW, Subhedar NV, Shaw NJ (2000) Respiratory syncytial virus infection in high risk infants and the potential impact of prophylaxis in a United Kingdom cohort. Arch Dis Child 83: 313-316.

12. Wang EE, Law BJ, Stephens D (1995) Pediatric Investigators Collaborative Network on Infections in Canada (PICNIC) prospective study of risk factors and outcomes in patients hospitalized with respiratory syncytial viral lower respiratory tract infection. J Pediatr 126: 212-219.

13. Hall CB, Weinberg GA, Blumkin AK (2013) Respiratory syncytial virusassociated hospitalizations among children less than 24 months of age. Pediatrics 132: 341-348.

14. Mandelberg A, Tal G, Witzling M (2003) Nebulized 3\% hypertonic saline solution treatment in hospitalized infants with viral bronchiolitis. Chest 123: 481-487.

15. Tal G, Cesar K, Oron A, Houri S, Ballin A (2006) Hypertonic saline/ epinephrine treatment in hospitalized infants with viral bronchiolitis reduces hospitalization stay: 2 years experience. Isr Med Assoc J 8: $169-173$.
16. Zhang L, Mendoza-Sassi RA, Wainwright C, Klassen TP (2013) Nebulised hypertonic saline solution for acute bronchiolitis in infants. Cochrane Database Syst Rev 7: CD006458.

17. Chen YJ, Lee WL, Wang CM, Chou HH (2014) Nebulized hypertonic saline treatment reduces both rate and duration of hospitalization for acute bronchiolitis in infants: An updated meta-analysis. Pediatr Neonatol 55: 431-438.

18. Ralston SL, Lieberthal AS, Meissner HC (2014) Clinical practice guideline: the diagnosis, management, and prevention of bronchiolitis. Pediatrics 134: e1474-e1502.

19. Gonzalez CD, Gonzalez Perez-Yarza E (2001) Acute bronchiolitis: fundamentals of a rational protocol. An Esp Pediatr 55: 355-364.

20. Silver AH, Esteban-Cruciani N, Azzarone G (2015) 3\% Hypertonic Saline Versus Normal Saline in Inpatient Bronchiolitis: A Randomized Controlled Trial. Pediatrics 136: 1036-1043.

21. Everard ML, Hind D, Ugonna K (2014) SABRE: A multicentre randomised control trial of nebulised hypertonic saline in infants hospitalised with acute bronchiolitis. Thorax 69: 1105-1112.

22. Hall CB, Weinberg GA, Iwane MK (2009) The burden of respiratory syncytial virus infection in young children. N Engl J Med 360: 588-598.

23. Brooks AM, McBride JT, McConnochie KM, Aviram M, Long C (2009) Predicting deterioration in previously healthy infants hospitalized with respiratory syncytial virus infection. Pediatrics 104: 463-467.

24. Kuzik BA, Al-Qadhi SA, Kent S (2007) Nebulized hypertonic saline in the treatment of viral bronchiolitis in infants. J Pediatr 151: 266-270.

25. Zhang L, Mendoza-Sassi RA, Wainwright C, Klassen TP (2008) Nebulized hypertonic saline solution for acute bronchiolitis in infants. Cochrane Database Syst Rev 4: CD006458.

26. Luo Z, Fu Z, Liu E (2011) Nebulized hypertonic saline treatment in hospitalized children with moderate to severe viral bronchiolitis. Clin Microbiol Infect 17: 1829-1833.

27. Christakis DA, Cowan CA, Garrison MM, Molteni R, Marcuse E (2005) Variation in inpatient diagnostic testing and management of bronchiolitis. Pediatrics 115: 878-884.

28. Brand PL, Vaessen-Verberne AA (2000) Differences in management of bronchiolitis between hospitals in The Netherlands. Dutch Paediatric Respiratory Society. Eur J Pediatr 159: 343-347.

29. Willson DF, Horn SD, Hendley JO, Smout R, Gassaway J (2001) Effect of practice variation on resource utilization in infants hospitalized for viral lower respiratory illness. Pediatrics 108: 851-855. 